\title{
Erratum to: A Novel Bikinin Analogue for Arabidopsis and Rice with Superior Plant Growth-Promoting Activity
}

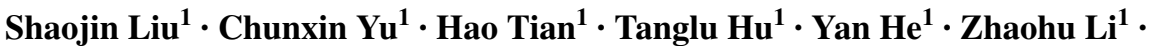

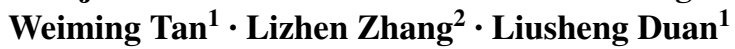

Published online: 22 August 2017

(C) Springer Science+Business Media, LLC 2017

\section{Erratum to: J Plant Growth Regul \\ DOI 10.1007/s00344-017-9715-5}

The original version of this article unfortunately contained a mistake in the structure of compound 8a and 8c in Fig. 2. The structure of $\mathbf{8 a}$ and $\mathbf{8 c}$ lacked an oxygen molecule in the amide and ester, respectively.

The corrected Fig. 2 was attached below.

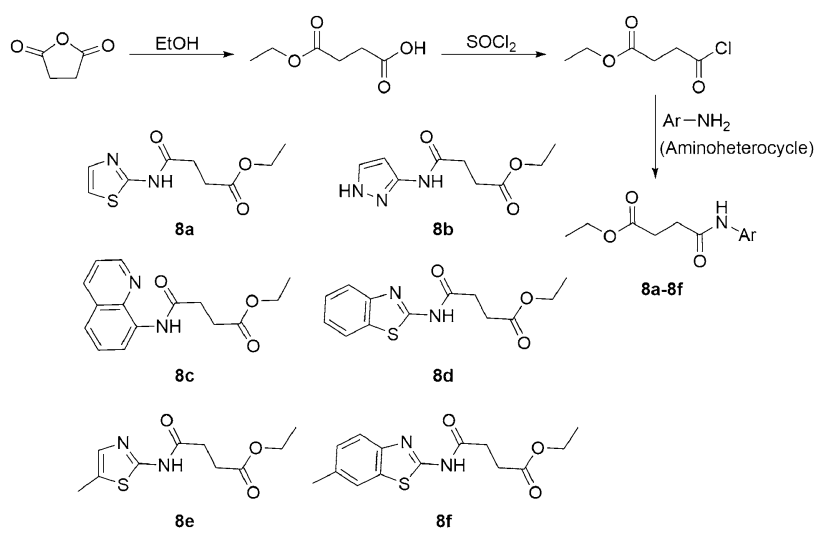

Fig. 2 Synthesis of bikinin analogues

The online version of the original article can be found under doi:10.1007/s00344-017-9715-5.

Liusheng Duan

duanlsh@cau.edu.cn

Shaojin Liu

liusj9112@126.com; jxnclsj@cau.edu.cn

1 State Key Laboratory of Plant Physiology and Biochemistry/

Engineering Research Center of Plant Growth

Regulators, Ministry of Education/College of Agronomy

and Biotechnology, China Agricultural University,

Beijing 100193, People's Republic of China

2 College of Resources and Environmental Sciences,

China Agricultural University, Beijing 100193,

People's Republic of China 